\title{
Chromosome 6U from Aegilops geniculata Roth Carrying Powdery Mildew Resistance in Bread Wheat
}

\author{
Tsvetana Stoilova*1) and Penko Spetsov²) \\ 1) Institute of Genetics, Bulgarian Academy of Sciences, 1113 Sofia, Bulgaria \\ 2) Dobroudja Agricultural Institute, 9520 General Toshevo, Bulgaria
}

\begin{abstract}
The production and isolation of a wheat-Aegilops geniculata disomic addition line and of monosomic substitution line resistant to powdery mildew at the seedling and adult plant stages are described. Cytological analysis revealed the presence of an acrocentric chromosome in the resistant derivatives. Polyacrylamide gel electrophoretic analysis indicated differences in the $\beta$-zone of the reduced by mercaptoethanol treatment seed protein pattern between the wheat parent cv. Trakya and the resistant derivatives. A component with a high staining intensity in the $\beta$-zone was assumed to be a marker for the chromosome 6 of Ae. geniculata. The isoenzyme activity at the Got-1 and Est-4 loci of the lines was lower than that of wheat. By analyzing the isoenzymes of the Amp-1 locus of the addition plants, a quantitative marker of Ae. geniculata 6U chromosome was identified. The progeny of the plants with the $2 n=43$ and $2 n=42$ chromosomes carrying the chromosome $6 \mathrm{U}$ added or mono-substituted for the wheat $6 \mathrm{D}$ chromosome segregated for powdery mildew resistance. The mono-and/or double conditions for this chromosome could be maintained by selecting resistant plants in the segregated populations.
\end{abstract}

Key Words: Aegilops geniculata, wheat, powdery mildew resistance, isoenzymes, chromosome 6U.

\section{Introduction}

Powdery mildew is a destructive foliar disease caused by a biotrophic parasitic fungus Blumeria graminis f. sp. tritici (syn. Erysiphe graminis f. sp. tritici) (Speer 1973). Although chemicals are effective against this disease, the use of host resistance has remained an economical and environmental safe device of control in practice.

Genes for powdery mildew resistance, i.e. $P m$ genes have been described at 33 loci in common wheat (Liu et al. 2002, Singrun et al. 2004, Zhu et al. 2005). Some of them have been utilized in commercial wheat varieties, but were soon overcome by new pathogen races. Strategies including cultivar mixing, diversification or gene pyramiding may increase the resistance to powdery mildew (Priestley and Bayles 1998, Hsam and Zeller 2002).

The genus Aegilops comprises 22 species, most of which are potential donors of resistance to foliar diseases (Van Stageren 1994, Valkoun and Bedo 2001, Zaharieva et al. 2003). One of them is Aegilops geniculata Roth (syn. Ae. ovata $\mathrm{L}$.), a wild allotetraploid species $(2 \mathrm{n}=28$, UUMM). The species can be crossed to common wheat, and various derivatives such as addition, substitution and translocation lines have been obtained (Mettin et al. 1977, Friebe and Heun 1989, Friebe et al. 1996, McIntosh et al. 2001). Up to

Communicated by H. Tsujimoto

Received February 23, 2006. Accepted July 25, 2006.

*Corresponding author (e-mail: tzstoilova@yahoo.com) now, only the Pm29 gene from Ae. geniculata had been transferred to common wheat (Zeller et al. 2002). However, the resistance could not be traced back to a specific chromosome, because of the high level of structural variation in the chromosome complements of the A and B genomes of the addition lines (Friebe and Heun 1989).

Identification of alien introgressions has been greatly facilitated by the use of seed storage protein patterns and isoenzymes as markers of alien genes in the wheat background and for determining the homoeology of the added or substituted alien chromosomes. Gliadin components and glutenin subunits were used as markers for powdery mildew or rust resistance due to putative introgressions from Ae. turcomanica (Vahl et al. 1999), Ae. umbellulata (Stoilova et al. 1999, Ozgen et al. 2004), Ae. tauschii (Pfluger et al. 2001), etc. Using isoenzymes as markers of nearly all the homoeologous chromosomes in wheat, Schmidt et al. (1993) and William and Mujeeb-Kazi (1996) developed biochemical diagnostics for Ae. markgrafii and Ae. variabilis chromosomes in the addition lines or amphiploids. Alcohol dehydrogenase (ADH), Est-5 and Got-3 isoenzymes encoded by genes of the homoeologous groups 4 and 3 chromosomes were found to be suitable markers for alien introgression from Ae. ventricosa and Ae. geniculata (Mena et al. 1989, Stoilova 2002). Finally the gliadins and many enzyme loci have been classified by their variability for possible location on the genetic map of wheat and for use in alien-wheat comparisons (Gale and Sharp 1988).

In the present study, we produced and characterized 
derivatives resistant to powdery mildew in a cross between Triticum aestivum cv. Trakya and Ae. geniculata. The chromosome morphology, protein patterns and Amp-1, Got-1 and Est-4 isoenzymes used as markers for the homoeologous group of chromosome 6 enabled to demonstrate that the alien acrocentric chromosome was a carrier for powdery mildew resistance in wheat.

\section{Materials and Methods}

\section{Plant materials}

Aegilops geniculata $(2 \mathrm{n}=28, \mathrm{UUMM})$ accession 2233 from the collection of the Dobroudja Agricultural Institute General Toshevo, Bulgaria, was used as a source of resistance to powdery mildew $(P m)$. The species was crossed as a male parent to $T$. aestivum $\mathrm{cv}$. Trakya, a winter type cultivar registered in Bulgaria in 1977 and considered to be susceptible to powdery mildew (Petrova et al. 2000). First, the amphiploid (AD) was obtained by colchicine treatment of the $\mathrm{F}_{1}$ hybrid. Backcross $1\left(\mathrm{BC}_{1}\right)$ plants were produced using the amphiploid as pistillate parent and Trakya as pollen parent. Two $\mathrm{BC}_{1}$ plants expressing resistance to powdery mildew at the seedling and adult plant stages were emasculated and pollinated with $\mathrm{cv}$. Trakya to produce $\mathrm{BC}_{2}$ seeds. These backcross seeds were germinated and seedlings with $2 \mathrm{n}=$ 43-46 chromosomes were transplanted and further evaluated for $\mathrm{Pm}$ resistance. Selfing of plants with $2 \mathrm{n}=44$ chromosomes resulted in the production of a large number of $\mathrm{BC}_{2} \mathrm{~F}_{2}$ plants, enabling the selection of individuals with resistance to powdery mildew. The following nullisomic-tetrasomic lines of the wheat cultivar Chinese Spring (CS) were used as subsidiary genetic systems: CSN6A/T6B, CSN6A/T6D, CSN6B/T6D, CSN6D/T6A, CSN6D/T6B and the addition line CS6U (addition of Ae. umbellulata chromosome 6U). These stocks were originally supplied by Dr. E. R. Sears and then maintained at the Institute of Genetics, Sofia, Bulgaria.

For chromosome identification, root tips of the seedlings were pretreated with a 1-bromonaphthalene solution and stained by the conventional Feulgen method.

\section{Powdery mildew resistance}

The resistance to powdery mildew caused by Blumeria graminis f. sp. tritici was screened at the seedling and adult plant stages. Plants at the two-three leaf stages were evaluated in the greenhouse in the natural infection background. Common wheat variety Sadovska ranozreika-4 as pathogen spreader and standard for high susceptibility to powdery mildew, was placed at several sites in the greenhouse. Mildew attack was recorded twice, once at the 2-leaf stage, and once at the 3-leaf stage. The ratings were performed using a scale from 0 (immune) to 9 (susceptible) (Tomerlin et al. 1984). Disease ratings of the plants were grouped into two classes- $\mathrm{R}$ (resistant) (0-6), and S (susceptible) (7-9).

The resistance at the adult plant stage was evaluated in a greenhouse under high natural disease epiphytotic conditions. The infection type (IT, $0-4$ ) and the disease infection severity (DIS) were estimated according to the method of Stakman et al. (1962). DIS was given in percentage from 0 to 100 , where 0 corresponds to the lack of infection, and 100 to the maximum degree of infection. Disease was assessed as a visual estimate of the percentage of the leaf area covered by colonies of Blumeria graminis f. sp. tritici (Bgt). The leaf areas analysed involved the top three leaves of adult plants at 10-day intervals between growth stages 51 and 61. The plants subjected to the evaluation were grouped into resistant $(\mathrm{R})$ with $\mathrm{IT}=0-2$ and DIS $=0-50$, and susceptible $(\mathrm{S})$ with IT $=3-4$ and DIS $=60-100$.

\section{Biochemical methods}

The proteins from wheat seeds were extracted and separated by polyacrylamide gel electrophoresis (PAGE) at $\mathrm{pH} 3.2$ according to the method of Cooper (1987). The extraction medium consisted of pyronine $\mathrm{G}(0.05 \%)$ in 2-chloroethanol $(20 \%)(\mathrm{w} / \mathrm{v})$ containing urea $(18 \%)$ and 2 -mercaptoethanol (1\%). The reduced by the 2-mercaptoethanol proteins were fractionated in 10\% PAGE, using the discontinuous system of Laemmli (1970). Gels were stained with $0.03 \%(\mathrm{w} / \mathrm{v})$ Coomassie Brilliant Blue R 250 in a methanol and acetic acid mixture $(5: 1)(\mathrm{v} / \mathrm{v})$.

The enzyme systems aminopeptidase-1 (Amp-1), glutamate oxaloacetate transaminase-1 (Got-1) and esterase4 (Est-4) were analyzed. Extracts for the analysis of the GOT and EST enzymes were prepared by grinding seeds at $4^{\circ} \mathrm{C}$ with $0.05 \mathrm{M}$ TRIS-HCL buffer $\mathrm{pH} 7.2$ containing supplements $-6 \mathrm{mM}$ ascorbic acid, $6 \mathrm{mM}$ cystein hydrochloride and 0.5 M sucrose (Rychter and Lewak 1969). The homogenates were centrifuged at $10,000 \mathrm{~g}$ for $20 \mathrm{~min}$. The clear supernatants were analyzed by vertical PAGE using a $10 \%$ gel and discontinuous buffer system of TRIS-EDTA-boric acid, pH 8. 3 (Peacock et al. 1965). After electrophoresis, the gels were stained for GOT and $\alpha$-naphthyl esterases by standard histochemical methods (Scandalios 1964, Shaw and Prassad 1970). The extracts for the analysis of aminopeptidase-1 (Amp-1) were prepared by grinding the seeds with $10 \mathrm{mM}$ dithiothreitol (DTT) in distilled water at room temperature for $1 \mathrm{~h}$ (Koebner and Martin 1989). For the visualization of

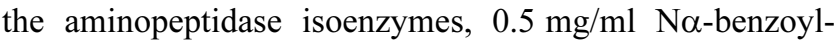
DL-arginine- $\beta$-naphthylamide (BANA) was used as a substrate. The investigation was performed using a Biotech Hoefer SE 600 apparatus (Pharmacia, Uppsala, Sweden) and an electrophoretic power source (EPS) 600. The gel plate with 15 wells measured $180 / 160 / 1.5 \mathrm{~mm}$.

For biochemical studies of cv. Trakya and Ae. geniculata, average seed samples were used. Individual kernels derived from selfed $\mathrm{BC}_{2} \mathrm{~F}_{2}$ plants with $2 \mathrm{n}=44$ chromosomes corresponded to the plants referred to as addition plants and seeds derived from selfed $\mathrm{BC}_{2} \mathrm{~F}_{2}$ plants with $2 \mathrm{n}=42$ and 43 chromosomes and the presence of the $a c$ chromosome corresponded to the plants referred to as substitution plants. The chemicals were supplied by Chemapol (Prague, Czech Republic) and Serva (Heidelberg, Germany). 


\section{Results}

In total $54 \mathrm{BC}_{1}$ plants were investigated and two plants expressing the resistance were selected and backcrossed. The two selected $\mathrm{BC}_{2}$ plants $(2 \mathrm{n}=44)$ were also resistant to powdery mildew at the seedling and adult plant stages, compared with the wheat parent (Table 1) and all the plants in their selfed progeny were resistant to powdery mildew. Disomic addition plants accounted for about $65 \%$ of the progeny (data not shown). Comparison of the karyotypes revealed that the acrocentric chromosome $(a c)$ in the resistant derivatives was similar to the ac chromosome in the Ae. geniculata parent and the $\mathrm{F}_{1}$ hybrid (Trakya $\times$ Ae. geniculata) (Fig. 1, Fig. 2 and Fig. 3). Wheat satellite chromosomes $1 \mathrm{~B}$ and $6 \mathrm{~B}$ were also visualized and distinguished from the alien $1 \mathrm{U}$ and $5 \mathrm{U}$ satellite chromosomes, as well as from the ac chromosome in the hybrid (Fig. 2). The cytological analysis revealed the presence of an acrocentric pair of chromosomes in all the checked plants with $2 \mathrm{n}=44$ chromosomes. This chromosome may be a carrier of resistance genes to powdery mildew. Plants with $2 n=42$ and 43 chromosomes were isolated to produce a disomic substitution for the alien chromosome. Their progeny segregated for the $P m$ resistance (Table 1). Individuals with the acrocentric chromosome under the double or monosomic condition expressed always $\mathrm{Pm}$ resistance, irrespective of their chromosome complement.

Mitrophanova (1976) demonstrated that the gliadin components from the $\beta$ - and $\alpha$-zones in the cv. Chinese Spring are controlled by chromosomes of the first and sixth homoeologous groups. Almost all the components of the $\beta$ zone are under the control of two or three chromosomes of the wheat genome. By analyzing the phenotypes of the CSN6D/T6A, CSN6D/T6B lines and cv. CS, we observed that the slowest moving component from the $\beta$-zone of the euploid form (arrowhead) was controlled by chromosome 6D (Fig. 4, tracks 1-6). The wild species Ae. geniculata (track 8) displayed a clear banding pattern. A component specific for Ae. geniculata with a high staining intensity (arrowhead in the figure) was detected in both, the amphiploid and the addition (tracks 10-12) and mono-substitution (tracks 13-15) plants. Compared with the pattern of cv. Trakya, the components of the $\beta$-zone of the addition plants (tracks 10 12) were more prominent.

Based on the electrophoretic pattern of the isoenzymes at the Got-1 locus, the cv. Trakya and Ae. geniculata differed in the number of isoenzymes, four and two, respectively (Fig. 5, tracks 2, 3, 9, 10). From the quantitative viewpoint, the Got-1 pattern in the addition (tracks 5-8) and substitution plants (tracks 11-13) was similar to that of wheat, but the activity was lower. The isoenzyme nearest to the anode showed a fuzzy pattern in the resistant addition and mono-substitution plants (arrow in the figure), while in the $\mathrm{cv}$. Trakya the pattern was clear.

Based on the banding pattern of the Est-4 locus, three isoenzymes were recognized in cv. Trakya (Fig. 6, track 5). In the pattern of Ae. geniculata, two isoenzymes with a low activity which corresponded to their homoeologous in the wheat, were visualized. The phenotype of the addition (tracks 1-4) and mono-substitution (tracks 7-10) plants was similar to that of wheat at the Est-4 locus, although three among the isoenzymes displayed a lower activity (arrowhead in the figure).

At the Amp-1 locus in the CS6U addition line (Fig. 7,

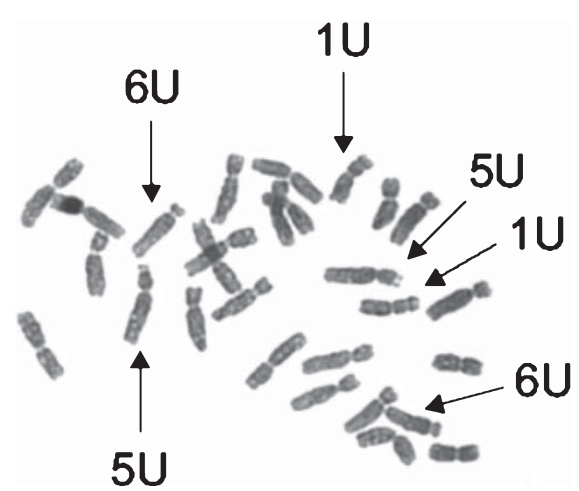

Fig. 1. Chromosome complement of Ae. geniculata accession 2233 $(2 n=28)$ : arrows point to the acrocentric $6 \mathrm{U}$ and satellite $1 \mathrm{U}$ and $5 \mathrm{U}$ pairs of chromosomes.

Table 1. Incidence of powdery mildew in parents and derivatives from the cross T.aestivum $\times$ Ae.geniculata under greenhouse conditions

\begin{tabular}{|c|c|c|c|c|c|c|c|c|}
\hline \multirow[t]{2}{*}{ Genotypes } & \multirow[t]{2}{*}{ Line no. } & \multirow[t]{2}{*}{$2 n$} & \multirow[t]{2}{*}{ Parentage } & \multicolumn{2}{|c|}{ Powdery mildew reaction } & \multicolumn{3}{|c|}{$\begin{array}{l}\text { Chromosome number and powdery } \\
\text { mildew reaction in selfed progeny }\end{array}$} \\
\hline & & & & Seedling ${ }^{1)}$ & Adult plant $\left.{ }^{2}\right)$ & $2 n$ & Seedling & Adult plant \\
\hline Parent & - & 42 & Triticum aestivum cv. Trakya & $\mathrm{S}$ & $\mathrm{S}$ & 42 & $\mathrm{~S}$ & $\mathrm{~S}$ \\
\hline Parent & - & 28 & Aegilops geniculata accession 2233 & $\mathrm{R}$ & $\mathrm{R}$ & 28 & $\mathrm{R}$ & $\mathrm{R}$ \\
\hline Amphidiploid & $\mathrm{AD}$ & 70 & $\mathrm{C}_{1}$ Trakya $\times$ Ae.geniculata & $\mathrm{R}$ & $\mathrm{R}$ & $68-70$ & $\mathrm{R}$ & $\mathrm{R}$ \\
\hline Disomic addition & $12-4$ & 44 & $\mathrm{BC}_{2}$ Trakya $\times$ Ae.geniculata & $\mathrm{R}$ & $\mathrm{R}$ & $42-44$ & $\mathrm{R}$ & $\mathrm{R}$ \\
\hline Disomic addition & $12-5$ & 44 & $\mathrm{BC}_{2}$ Trakya $\times$ Ae.geniculata & $\mathrm{R}$ & $\mathrm{R}$ & $43-44$ & $\mathrm{R}$ & $\mathrm{R}$ \\
\hline Mono-substitution & $12-\mathrm{z}$ & 43 & $\mathrm{BC}_{2} \mathrm{~F}_{2}$ Trakya $\times$ Ae.geniculata & $\mathrm{R}$ & $\mathrm{R}$ & $42-44$ & $S, R$ & S, R \\
\hline Mono-substitution & $2-4$ & 42 & $\mathrm{BC}_{2} \mathrm{~F}_{2}$ Trakya $\times$ Ae.geniculata & $\mathrm{R}$ & $\mathrm{R}$ & $41-42$ & $S, R$ & $\mathrm{~S}, \mathrm{R}$ \\
\hline
\end{tabular}

1) $\mathrm{R}=$ resistant (ratings $0-6$ ), $\mathrm{S}=$ susceptible (ratings 7-9);

2) Infection type (IT) and disease infection severity (DIS) were estimated for powdery mildew resistance of the adult plant stage: $\mathrm{R}=$ resistant $(\mathrm{IT}=0-2$, DIS =0-50); $\mathrm{S}=$ susceptible $(\mathrm{IT}=3-4, \mathrm{DIS}=60-100)$; Susceptible standard cv. Sadovska ranozreika-4 showed S type of reaction to powdery mildew at both stages. 


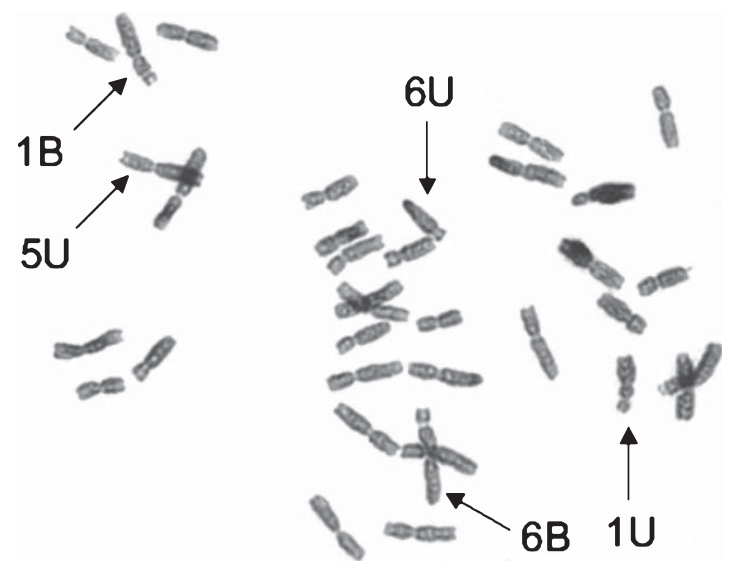

Fig. 2. Chromosome complement of $\mathrm{F}_{1}($ Trakya $\times$ Ae. geniculata $): 2 \mathrm{n}=$ 35 ; arrows point to the wheat and alien satellite and acrocentric $6 \mathrm{U}$ chromosomes.

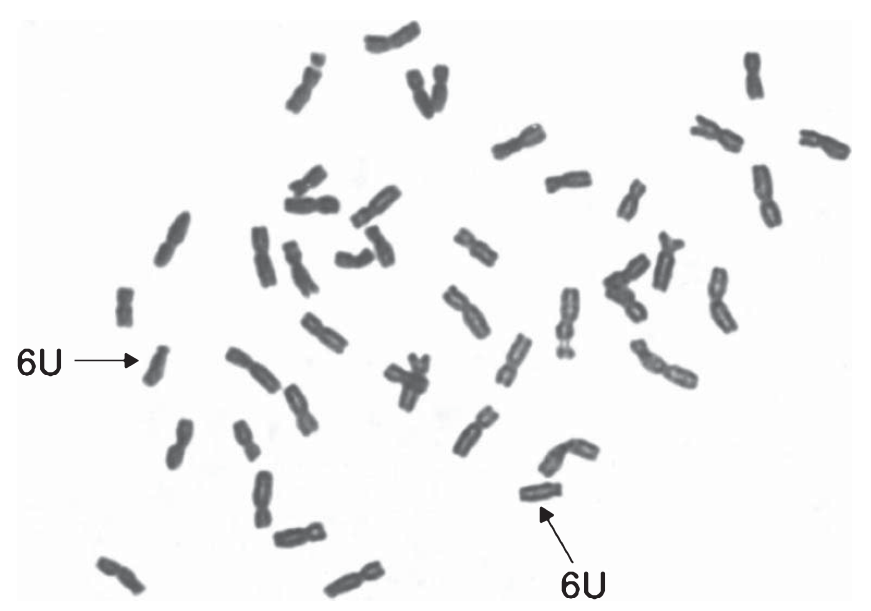

Fig. 3. Chromosome complement of a disomic addition line (Trakya $\times$ Ae. geniculata): $2 \mathrm{n}=44$; arrows point to the acrocentric $6 \mathrm{U}$ chromosome pair derived from Ae. geniculata.

track 2), an isoenzyme with a high activity was visualized, compared with the very low activity in CS. It is, therefore, suggested that the isoenzyme examined in the CS6U line is under the control of chromosome $6 \mathrm{U}$ and could be used as a marker. The patterns of cv. Trakya and Ae. geniculata revealed a clear specificity (tracks 3,4 ). The band showing a high staining intensity in CS 6U was detected in the two parents, although its intensity in Ae. geniculata was considerably high. The isoenzyme activity of the addition plants (tracks 5,6) was as high as that of the alien species, while the activity of the substitution plants (tracks 7,8 ) did not differ from that of wheat.

\section{Discussion}

The few $P m$ genes that have been transferred to a hexaploid cultivar, could be relatively expoited in breeding programs. However, transfer of the $P m$ resistance gene, from species with the $\mathrm{U}$ and $\mathrm{M}$ genomes to the AABBDD genetic

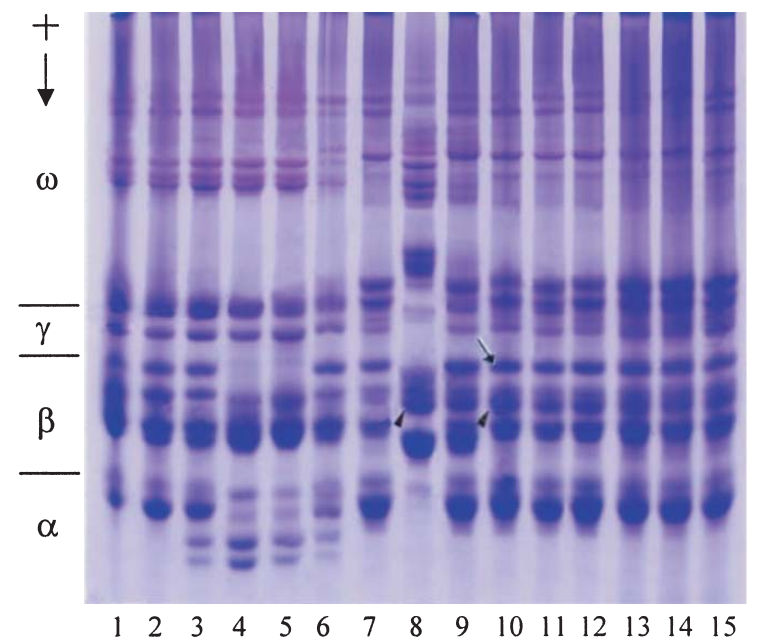

Fig. 4. Reduced by mercaptoethanol seed protein pattern of wheat lines with the addition and mono-substitution of chromosome 6 of Ae geniculata (8): addition plants (10-12); substitution plants (13-15); cv. Trakya (7); cv. CS (6); AD (9). Subsidiary genetic systems: CSN6A/T6B (1); CSN6A/T6D (2); CSN6B/ T6D (3); CSN6D/T6A (4); CSN6D/T6B (5); arrowheads point to the specific component for Ae. geniculata (8) detected in the resistant addition and substitution plants.

Got-2

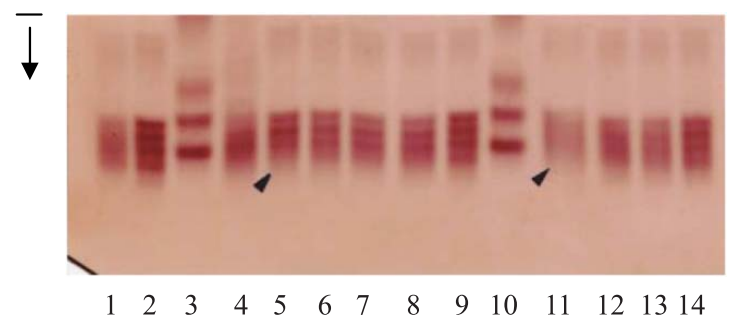

Fig. 5. Glutamate oxaloacetate transaminase (GOT-1) seed isoenzyme pattern of wheat lines with the addition and mono-substitution of chromosome 6 of Ae. geniculata $(3,10)$; cv. Trakya $(2,9)$; $\mathrm{AD}(4)$; cv. CS (1); arrowheads point to the isoenzymes with a fuzzy pattern in the addition (5-8) and substitution (11-14) plants due to the influence of chromosome 6 of Ae. geniculata (3).

background of wheat has been found to be very difficult (Zeller et al. 2002). The ac chromosome in the resistant lines seemed to be that of the alien species used. Based on its unique morphology, this chromosome could correspond to chromosome 6U of Ae. geniculata. Friebe et al. (1995) showed that the $\mathrm{U}$ genome chromosomes of Ae. geniculata were similar in size, arm ratio and C-banding pattern, compared with those of the diploid progenitor species Ae. umbellulata. These similarities were used to assign the U genome chromosomes in the CS addition lines to the various homoeologous groups of wheat. Moreover, the $6 \mathrm{U}$ chromosome of Ae. umbellulata was extremely acrocentric, with a long-toshort arm ratio of 5:1 (Friebe et al. 1995). Furthermore, the lack of aberrations in the Ae. geniculata chromosomes during the isolation of the addition lines was emphasized (Friebe et al. 1999). During the investigation, we observed 


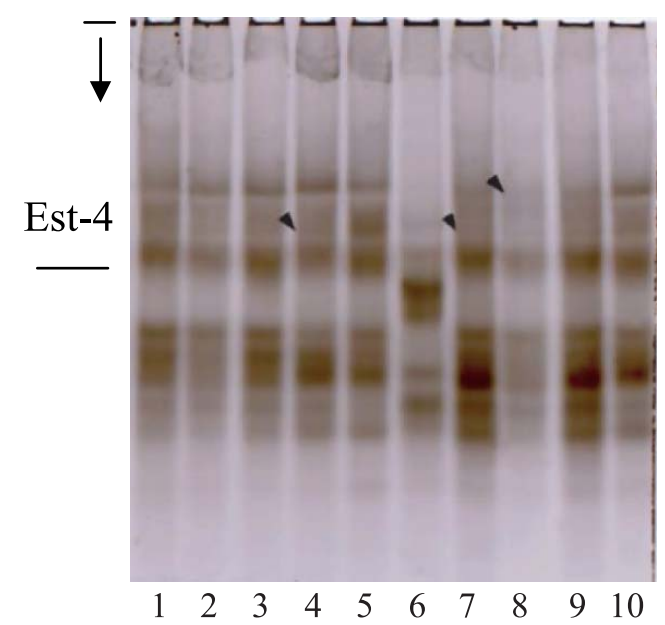

Fig. 6. Esterase (Est-4) seed isoenzyme pattern of wheat lines with the addition and mono-substitution of chromosome 6 of Ae. geniculata (6); cv. Trakya (5); arrowheads point to the lower isoenzyme activity in the addition (1-4) and substitution plants $(7-10)$ due to the influence of chromosome 6 of Ae. geniculata (6).

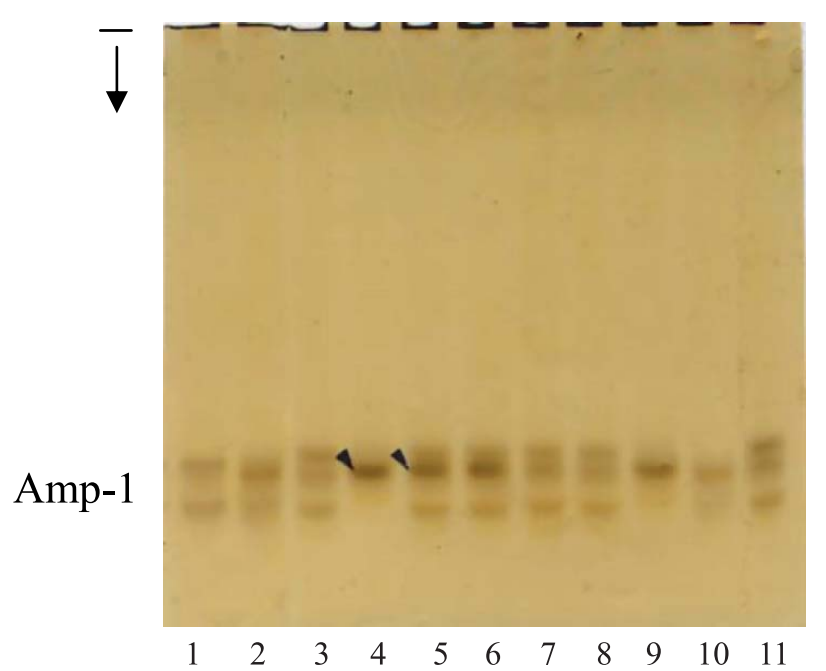

Fig. 7. Seed aminopeptidase (Amp-1) isoenzyme pattern in wheat lines with the addition and mono-substitution of $6 \mathrm{U}$ chromosome of Ae. geniculata (4, 9): cv. Trakya (3, 11); addition plants (5-6); substitution plants (7-8); cv. CS (1); addition line CS6U (2, 10); The higher activity of the isoenzyme (arrowheads) is due to the presence of chromosome $6 \mathrm{U}$ of Ae. geniculata (4).

that the $a c$ chromosome pair was present only in the plants with $2 \mathrm{n}=44$ chromosomes, and in a few cases, in the genotypes with $2 \mathrm{n}=43$ and 42 chromosomes. The experimental data supported the statement of Friebe et al. (1999) that the $6 \mathrm{U}^{\mathrm{g}}$ chromosome was only present under monosomic conditions. Thus, we suggest that the $a c$ chromosome added to and mono-substituted in the cv. Trakya background corresponds to the $6 \mathrm{U}$ chromosome transferred from Ae. geniculata. In the mono-substitution plants, the two satellite chromosomes $1 \mathrm{~B}$ and 6B were easily recognized. Thus, chromo- somes $6 \mathrm{~A}$ or $6 \mathrm{D}$ may have possibly been substituted for the alien $a c$ chromosome. The plants with $2 \mathrm{n}=43$ and 42 chromosomes that carry the $a c$ chromosome $6 \mathrm{U}$ under monosomic conditions segregated for $\mathrm{Pm}$ resistance. The mono-and/or double conditions for this chromosome could be maintained in segregated populations by selecting the resistant plants. The plants with $2 \mathrm{n}=44$ and 43 chromosomes showed an identical protein phenotype, which indicated that one and the same chromosome was added or substituted. The higher staining intensity of the slowest moving $\beta$ component, controlled only by chromosome $6 \mathrm{D}$ might indicate that the chromosome that had been added to or monosubstituted in the plants was a chromosome belonging the group 6 of Ae. geniculata. Therefore, we considered that the $\beta$-component specific for Ae. geniculata that was observed in all the resistant lines could be used as a marker for alien chromosome introgression. Previously, it had been demonstrated that the Got-1 and Est-4 isoenzymes were biochemical markers of the sixth homoeologous group of chromosomes in wheat (Hart 1975, Ainsworth et al. 1984). The lower activity of the Got-1 isoenzymes, especially the fastest moving one, and Est-4 isoenzymes in the addition and mono-substitution plants was probably due to the influence of chromosome 6 of Ae. geniculata. Using nulli-tetrasomic lines of the cv. CS, Koebner and Martin (1989) determined that the $6 \mathrm{D}$ chromosome of wheat was responsible for the genetic control of the second of the three Amp-1 isoenzymes. The higher activity of the second Amp-1 isoenzyme in the CS6U line compared with that of the euploid CS cultivar supported the assumption that the $6 \mathrm{U}$ chromosome of Ae. geniculata was involved in the genetic control. By analogy, the activity of the homoeologous isoenzyme of Ae. geniculata in the addition plants indicated the presence of chromosome $6 \mathrm{U}$. This conclusion was in agreement with the cytological results showing that the $a c$ chromosome in the derivatives might correspond to the $6 \mathrm{U}$ chromosome from Ae. geniculata. It appeared that the Amp-1 isoenzyme encoded by the $6 \mathrm{D}$ wheat chromosome was homoeoallelic to the $6 \mathrm{U}$ chromosome of Ae. geniculata. The nearly identical phenotype of the mono-substitution plants with that of wheat may be ascribed to the fact that the alien $6 \mathrm{U}$ chromosome did not genetically compensate for the 6D wheat chromosome or that the investigated plants lacked the alien chromosome as a result of segregation. The results for the reduced seed proteins showed the presence of chromosome 6 of Ae. geniculata in the mono-substitution plants and the influence of the same chromosome on the isoenzyme activity of the Got-1 and Est-4 loci. Therefore, we considered that the first assumption could account for the Amp-1 phenotype of the mono-substitution plants.

In summary, the results from the cytological and biochemical investigations suggested that the $6 \mathrm{U}$ chromosome of Ae. geniculata was added and mono-substituted for the wheat 6D chromosome in the resistant derivatives and may be a source of resistance to powdery mildew. 


\section{Acknowledgements}

The research was partly funded by a grant from the International Atomic Energy Agency - Vienna (project $10755 / \mathrm{R})$. The assistance of Mrs. S. Stancheva is greatly acknowledged.

\section{Literature Cited}

Ainsworth,C., M.Gale and S.Baird (1984) The genetic control of grain esterases in hexaploid wheat. 1. Allelic variation. Theor. Appl. Genet. 68: 219-226.

Cooper, S.R. (1987) Report of the Rules of Committee 1983-1986. Seed Sci. and Technol. 15: 555-557.

Friebe,B. and M.Heun (1989) C-banding pattern and powdery mildew resistance of Triticum ovatum and four T. aestivum-T. ovatum chromosome addition lines. Theor. Appl. Genet. 78: 417-424.

Friebe, B., J.Jiang, N. Tuleen and B.S.Gill (1995) Standard karyotype of Triticum umbellulatum and the identification of T. umbellulatum chromatin in common wheat. Theor. Appl. Genet. 90: 150-156.

Friebe, B., J.Jiang, W.J.Raupp, R.A.McIntosh and B.S.Gill (1996) Characterization of wheat-alien translocations conferring resistance to diseases and pests: current status. Euphytica 91: 5987.

Friebe,B., N.A.Tuleen and B.S.Gill (1999) Development and identification of a complete set of Triticum aestivum-Aegilops geniculata chromosome addition lines. Genome 42: 374-380.

Gale,M.D. and P.J.Sharp (1988) Genetic markers in wheat - developments and prospects. In "Proc. $7^{\text {th }}$ Int. Wheat Genet. Symp." Miller,T.E. and K.D.D.Koebner (eds.), Cambridge, England 13-19 July 1988.

Hart,G.E. (1975) Glutamate oxaloacetate transaminase isozymes in Triticum: Evidence for multiple systems of triplicate structural genes in hexaploid wheat. In "Isozymes III Developmental Biology” Market,C. (ed.). Acad. Press Inc., New York. p. 637657.

Hsam, S.L.K. and F.J.Zeller (2002) Breeding for powdery mildew resistance in common wheat (Triticum aestivum L.) In "The powdery mildews - a comprehensive treatise" Belanger,R.R., W.R.Bushnell, A.J.Dik and T.L.W.Carver (eds.), The APS press, St. Paul, Minnesota.

Koebner,R.M.D. and P.K.Martin (1989) Chromosomal control of the aminopeptidases of wheat and its close relatives. Theor. Appl. Genet. 78: 657-664.

Laemmli,U.K. (1970) Cleavage of structural proteins during the assembly of the head of bacteriophage $T_{4}$. Nature 227: 680-685.

Liu,Z., Q.Sun, Z.Ni, E.Nevo and T.Yang (2002) Molecular characterization of a novel powdery mildew resistance gene $P m 30$ in wheat originated from wild emmer. Euphytica 123: 21-29.

McIntosh,R.A., K.M.Devos, J.Dubcovsky and W.J.Rogers (2001) Catalogue of gene symbols for wheat: 2001 Supplement. http:/ wheat.pw.Usda.gov/ggpages/wge/2001 upd.Htm

Mena,M., J.Orellana, I.Lopez-Braña, F.Garcia-Olmedo and A.Delibes (1989) Biochemical and cytological characterization of wheat/ Aegilops ventricosa addition and transfer lines carrying chromosome 4Mv . Theor. Appl. Genet. 77: 184-188.

Mettin,D., W.D.Blüthner, H.J.Schäfer, U.Buchholz and A.Rudolph (1977) Untersuchungen an Samenproteinen in der Gattung Aegilops. Tagungsber Akad. Landwirtschaftswiss DDR 158:
95-106.

Mitrophanova,O. (1976) Genetic control of gliadins in common wheat T. aestivum (L.), cultivar Chinese Spring. Tsitologia and Genetica 10: 244-247 (in Russian).

Ozgen,M., M.Yildiz, H.Ulukan and N.Koyuncu (2004) Association of gliadin protein patterns and rust resistance derived from Aegilops umbellulata Zhuk. in Triticum durum Desf. Breed. Sci. 54: 287-290.

Peacock,A., S.Bunting and R.Queen (1965) Serum protein electrophoresis on acrylamide gel patterns from normal human subjects. Science 147: 1451-1453.

Petrova, N., S.L.K.Hsam, P.Spetsov and F.J.Zeller (2000) Identification of powdery mildew and leaf rust resistance genes in common wheat (Triticum aestivum L. EM. Thell.) cultivars grown in Bulgaria and Russia. Plant Genet. Resour. Newsl. 122: 3235.

Pfluger, L.A., R.D Ovidio, B.Margiotta, R.Pena, A.Mujeeb-Kazi and D.Lafiandra (2001) Characterization of high- and lowmolecular weight glutenin subunits associated to the $\mathrm{D}$ genome of Aegilops tauschii in a collection of synthetic hexaploid wheats. Theor. Appl. Genet. 103: 1293-1301.

Priestley,R.H. and R.A.Bayles (1998) The contribution and value of resistant cultivars to disease control in cereals. In "Control of plant disease-costs and benefits" Cliford,B.C. and E.Lester (eds.), Blackwell Sci. Publ. Oxford, p. 53-65.

Rychter,A. and S.Levak (1969) Polyacrylamide gel electrophoresis on apple seed enzymes. Acta Biochem. Pol. 4: 333-338.

Scandalios,J.C. (1964) Tissue specific isoenzyme variations in maize. J. Hered. 55: 281-285.

Schmidt, J.Ch., V.Schubert and W.D.Blüthner (1993) Use of isoenzymes to characterize Triticum aestivum-Aegilops markgrafii addition lines. Biochem. Physiol. Pflanzen 188: 385-392.

Shaw,C. and R.Prassad (1970) Starch gel electrophoresis of enzymes - a compilation of recipes. Biochem. Genet. 4: 297-230.

Singrun, Ch., P.Rauch, A.Morgounov, S.Hsam and F.Zeller (2004) Identification of powdery mildew and leaf rust resistance genes in common wheat (Triticum aestivum L.). Wheat varieties from the Caucasus, Central and Inner Asia. Genet. Resour. Crop Evol. 51: 355-370.

Speer,E.O. (1973) Untersuchungen zur morphologie und systematic der Erysiphaceen I. Die gattung Blumeria Golovin und ichre typusart Erysiphe graminis DC. Sydowia 27: 1-6.

Stakman,E.C., D.M.Stewart and W.Q.Loegering (1962) Identification of physiologic races of Puccinia graminis var. tritici. Agric. Res. Serv. E617 (US Department of Agriculture: Washington DC).

Stoilova,Ts. (2002) Biochemical diagnostics of Aegilops geniculata Roth. chromosomes in homoeologous group 3 of the wheat. J. Genet \& Breed. 56: 359-364.

Stoilova, Ts., G. Ganeva, M. Vodenicharova, M. Todorova and A.Yankova (1999) Characterization of leaf rust resistant wheat lines with possible introgressions from Aegilops umbellulata by protein markers and N-banding. J. Genet \& Breed. 53: 327335 .

Tomerlin,J.R., M.A.El-Morshidy, J.G.Moseman, P.S.Baenziger and G.Kimber (1984) Resistance to Erisiphe graminis f. sp. tritici, Puccinia recondita f. sp. tritici, and Septoria nodorum in wild Triticum species. Plant Disease 68: 10-13.

Vahl,V., T.Bringezu and G.Muller (1999) Gliadins as biochemical markers for Aegilops turcomanica genes in wheat lines. Plant Breeding 118: 293-296. 
Valkoun,J.J. and Z.Bedo (2001) Wheat pre-breeding using wild progenitors. Euphytica 119: 1-2.

VanSlageren,M.W. (1994) Wild wheats: a monograph of Aegilops L. and Amblyopyrum (Jaub. \& Spach) Eig (Poaceae). Wageningen Agricultural University Papers 94-7, Wageningen, The Netherlands, 1-513.

William,M.D.H.M. and A.Mujeeb-Kazi (1996) Development of genetic stocks and biochemical markers to facilitate utilization of Aegilops variabilis in wheat improvement. Cytologia 61: 7-13.

Zaharieva, M., A.Dimov, P.Stankova, J.David and P.Monneveux (2003) Morphological diversity and potential interest for wheat improvement of three Aegilops L. species from Bulgaria. Genet. Resour. Crop Evol. 50: 507-517.

Zeller,F.J., L.Kong, L.Hartl, V.Mohler and S.L.K.Hsam (2002) Chromosomal location of genes for resistance to powdery mildew in common wheat (Triticum aestivum L. em Thell.) 7. Gene Pm29 in line Pova. Euphytica 123: 187-194.

Zhu,Z.D., R.H.Zhou, X.Y.Kong, Y.C.Dong and J.Z.Jia (2005) Microsatellite markers linked to 2 powdery mildew resistance genes introgressed from Triticum carthlicum accessions PS5 into common wheat. Genome 48: 585-590. 